\title{
Resistance of Flow in Teflon and Brass Tubes
}

\author{
Marion R. Brockman
}

\begin{abstract}
The results of a study of water flow through Teflon tubing to determine the existence of slip flow are reported. The coefficient of resistance was measured over the range of Reynolds number 2,000 to 120,000 . This investigation is composed of two series of tests. In the first series, resistance was measured in both laminar and turbulent flow. The second series dealt entirely with turbulent flow.

The resistance measurements determined for extruded Teflon tubing were compared with those of smooth-drawn brass tubing. The coefficients were so similar that it can be said that no slip flow exists for water flowing through Teflon tubing.
\end{abstract}

\section{Introduction}

The possibility of slip between a moving fluid and a solid boundary has been a subject of considerable speculation dating from very early times. The collective evidence from many investigators indicates that the fluid in contact with a surface does not move, regardless of the viscous tangential stress or the scouring action of turbulence, and that slip, if it is to exist, must be the rare exception.

It was the possibility of just such an exception that prompted the present investigation of the resistance to flow of water in a Teflon tube. Teflon (polytetrafluoroethylene) is a hydrophobic material. Not only does a drop of water not spread on a clean Teflon surface, but the water can be lifted free of the surface without breaking and without leaving a visible trace. This is evidence that the cohesive force of the water is greater than the adhesive force between the water and the Teflon. It is only the degree to which this behavior manifests itself that sets Teflon apart from many nonwetting materials. In this respect Teflon has an exceptionally low surface energy.

There was reason therefore to suppose that slip between Teflon and flowing water might exist and produce an observable effect. J. Kaye, ${ }^{1}$ who conducted an investigation similar to the present one, concluded that the friction coefficient for turbulent flow in a Teflon tube was in agreement with published values for smooth tubes and pipes in general, as far as could be judged from the precision of his measurements. It was felt, however, that Kaye's results were inconclusive because of the large scatter and because of the known fact that determinations of resistance coefficient by different investigators commonly differ by as much as 4 percent. It was decided therefore to reexamine the question and to do so by means of an experiment in which a direct comparison could be made with smooth brass tubes in the same experimental setup. The final outcome of the investigation was that there was no detectable difference to be found from this comparison. 1 J. Kaye, Flow resistance of Teflon, U. S. Naval Underwater Ordnance
Station, TM 46 (1953).

\section{Theoretical Considerations}

Assuming that slip does exist between flowing water and a nonwetting solid boundary, the most natural supposition to make is that slip arises from a tangential force proportional to the relative velocity. This is the hypothesis first advanced by Navier. If $u_{0}$ is the slip velocity and $\tau_{0}$ is the shearing stress per unit area on the wall, a slip coefficient may be defined by

$$
\tau_{0}=\beta u_{0}
$$

Because the stress must be due to shear in the fluid near the wall,

$$
\tau_{0}=\mu \frac{d u}{d y}
$$

where $\mu$ is the coefficient of viscosity, and $u$ is the tangential velocity at distances $y$ from the wall but near the wall. From eq (1) and (2) we may also write

$$
u_{0}=l \frac{d u}{d y}
$$

where $l=\mu / \beta$.

Equation (3) defines, after Lamb, ${ }^{2}$ a characteristic length, $l$, depending on the viscosity and properties of the boundary material when in contact with water or another liquid. As a characteristic length, $l$ must be considered among the variables of the flow system.

Accordingly, in capillary flow a dimensionless quantity to consider, among others, is the ratio $l / r$, where $r$ is the radius of the capillary bore. The importance of this has been discussed by Lamb. Let us consider the flows $Q_{1}$ and $Q_{2}$ through two capillaries of the same length, same radius, equal pressure differences, and with a common liquid traversing them. The only difference is that the material of one capillary is wetted and that of the

${ }^{2}$ H. Lamb, Hydrodynamics, 6th ed., p. 586 (Dover Publications, New York N. Y., 1932). 
other is not. The discharge, $Q_{2}$, through the capillary that is not wetted by the liquid is the greater in the ratio

$$
\frac{Q_{2}}{Q_{1}}=1+\frac{4 l}{r} \text {. }
$$

With capillaries of small bores, the effect of slip should be noticeable. Lamb, referring to the experiments of Poiseuille, concluded that the possibility of slip is absent. However, the capillaries used by Poiseuille were wetted by the liquid considered.

Similar evaluations for turbulent flow are difficult to carry out, because the laws of velocity distribution are essentially empirical. With common liquids and solids, the turbulent velocity distribution for small Reynolds number is described by the Blasius law,

$$
\frac{u}{u_{*}}=a_{1}\left(\frac{u_{*} y}{\nu}\right)^{1 / 7}
$$

where $y$ is distance from the wall, $\nu$ is the kinematic viscosity, and $u_{*}$ is the shear velocity defined by

$$
u_{*}=\sqrt{\tau_{0} / \rho} .
$$

This is the velocity outside the laminar sublayer of thickness $\delta_{1}$. If $u_{1}$ is the velocity when $y=\delta_{1}$, then

$$
\frac{u_{1}}{u_{*}}=\frac{u_{*} \delta_{1}}{\nu}
$$

Comparing eq (5) and (7),

$$
a_{1}=\left(\frac{u_{*} \delta_{1}}{\nu}\right)^{6 / 7}
$$

For a liquid not wetting the tube material, one may again suppose that

$$
\frac{u}{u_{*}}=a_{2}\left(\frac{u_{*} y}{\nu}\right)^{1 / 7} .
$$

The law of dependence on distance is still the same, but the coefficient $a_{2}$ is not the same as $a_{1}$. Let $\delta_{2}$ be the thickness of the laminar sublayer, $u_{1}$ the velocity at $y=\delta_{2}$, and $u_{0}$ the slip velocity; then

$$
u_{1}=u_{0}+\frac{d u}{d y} \delta_{2}
$$

Employing eq (1) and (2), and simplifying,

$$
\frac{u_{1}}{u_{*}}=\frac{u_{*}}{\nu}\left(l+\delta_{2}\right) .
$$

Thus, neglecting $(1 / 7)\left(l / \delta_{2}\right)$ with respect to 1 ,

$$
a_{2}=\left[\frac{u_{*}\left(l+\delta_{2}\right)}{\nu}\right]^{6 / 7} \text {. }
$$

Hence, the ratio of discharges through two pipes with constant pressure difference with radii and liquids the same is nearly

$$
\frac{Q_{2}}{Q_{1}}=\frac{a_{2}}{a_{1}}=\left(\frac{l+\delta_{2}}{\delta_{1}}\right)^{6 / 7} \text {. }
$$

Also, if we suppose that $\delta_{1}$ and $\delta_{2}$ are of like value, then approximately

$$
\frac{Q_{2}}{Q_{1}}=\left(1+\frac{6}{7} \frac{l}{\delta_{1}}\right)
$$

If slip is present, its effect will become more noticeable as $\delta_{1}$ becomes smaller. This will occur with increasing mean velocity for a tube of given diameter. If the velocity is fixed, $\delta_{1}$ decreases slowly with increasing diameter.

If the value of $\delta_{1}$ is introduced from eq (8),

$$
\frac{Q_{2}}{Q_{1}}=\left(1+c_{1} \frac{u_{*} l}{\nu}\right)
$$

where $c_{1}=(6 / 7) a_{1}^{-7 / 6}$. This illustrates the manner in which $l$ enters into the picture as a characteristic length in a Reynolds number based on shear velocity.

\section{Apparatus}

The test system used in this investigation is illustrated in figure 1. For the smaller values of Reynolds number, gravity flow from the constantlevel tank was used. A pump, located at the discharge end of the system was available for the higher velocities. Two swivel-joint diverters were employed to direct the discharge to either the volumetric tank or to the waste line. One diverter was placed immediately in front of the pump, the other mounted on the pump itself. Two valves, one for fine adjustments, were located at the exit end for controlling the flow.

A 4-in. pipe connected the system with the constant-level tank. In order to reduce turbulence and energy losses, the turn from the vertical to the horizontal direction was made with a large-radius bend. The entrance cone shown in figure 2 was located in the center of a flange on the 4-in. pipe, $8 \mathrm{ft}$ downstream from the bend. This provided for uniform velocity distribution at the entrance of the experimental tubing, where the diameter was reduced from 4 in. to 1 in.

The experimental tubing was composed of three sections. First, a $10-\mathrm{ft}$ length of 1 -in. brass tubing, then an 8-ft length of Teflon tubing, which was followed by another 10-ft length of brass tubing. All tubes were smooth in appearance and smooth to the touch, thus satisfying the usual criterion for hydrodynamic smoothness. Because the Teflon and brass tubes differed slightly in diameter, they were joined by special couplings shown in figure 3 . Diameter $B$ was machined to correspond to the inside diameter of the Teflon tubing. Diameter $C$ 


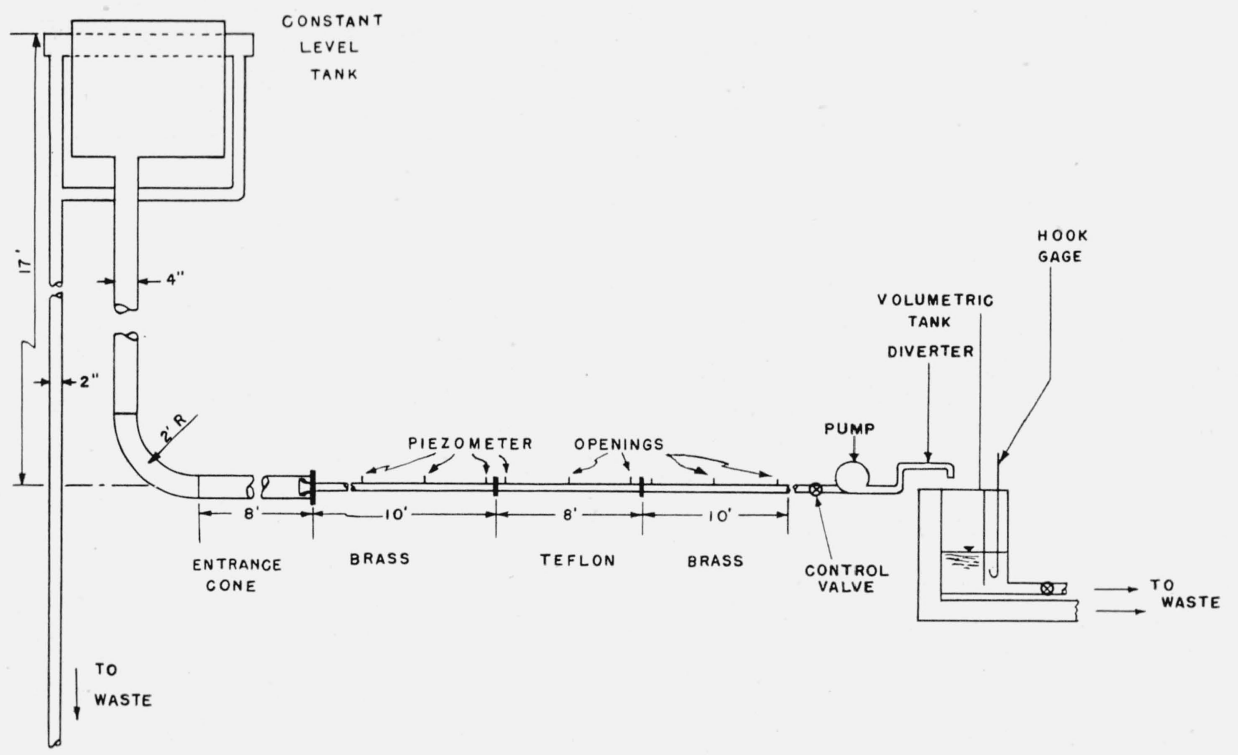

Figure 1. Arrangement of apparatus.

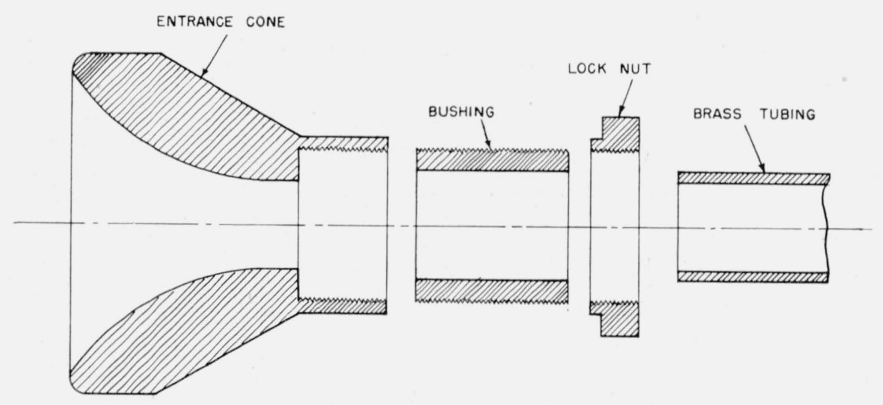

Figure 2. Entrance cone assembly.

was made the same as $B$ and then tapered out to match the inside diameter of the brass tubing. In this way discontinuities were avoided and the transition from one tube to the other was made gradually.

Piezometer openings were $1.0 \mathrm{~mm}$ in diameter, three in each section of tubing. These were connected by $1 / 4-$ in. copper tubing to both the water and mercury manometers. Selector cocks permitted the use of the proper set of manometers for its appropriate range of pressure. Both sets of manometer tubes were arranged in arcs of $1-\mathrm{m}$ radius. A cathetometer of special design mounted $1 \mathrm{~m}$ away served to measure the column heights of either set of manometers to the nearest $0.1 \mathrm{~mm}$.

The flow rate through the system was determined by means of a volumetric tank, which was calibrated by weighing the water and using a vernier hook gage for measuring depth. Time was measured with a stopwatch to the nearest $0.2 \mathrm{sec}$, and temperature was measured with a precision thermometer to the nearest $0.1 \mathrm{deg} \mathrm{C}$.

The mean inside diameters of the brass and Teflon tubes were obtained by measuring the amount of distilled water required to fill them while in a vertical

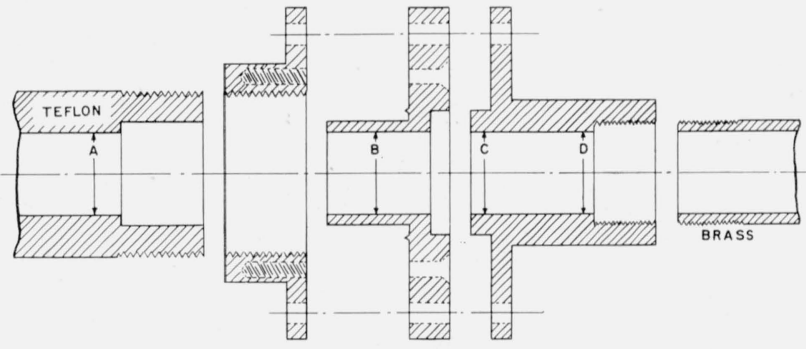

Figure 3. Teflon-to-brass coupling.

position. Water was poured into the tube from volumetric flasks. The residual water remaining in the flasks was taken into account, by calibration in the case of the larger flasks, and by weighing before and after emptying in the case of the smaller flasks. The mass of water contained in the larger flasks was computed by using the formula

$$
M_{f}=V(1+\alpha \Delta \theta) \rho_{\left(20^{\circ}+\Delta \theta\right)},
$$

where $M_{f}$ is the mass of water, $V$ is the volume of the flask at temperature $20^{\circ} \mathrm{C}, \alpha$ is the cubical coefficient of expansion of the flask, $\left(20^{\circ}+\Delta \theta\right)$ is the temperature of water in the flasks, and $\rho_{\left(20^{\circ}+\Delta \theta\right)}$ is the density of the water. The volume of water in the tube was computed on the basis of $V_{T}=M / \rho_{T}$, where $V_{T}$ is the volume of the tube, $M$ is the total mass of water in the tube, and $\rho_{T}$ is the density of the water at the tube temperature. Several determinations of the diameter of each tube were made, yielding the values given in table 1 . The mean of these as shown in the table was used in each case.

Prior to starting tests, all air was evacuated from the piezometer lines. Then the flow was regulated 
TABLE 1. Diameters of brass and Teflon tubes

\begin{tabular}{|c|c|c|}
\hline Brass 1 & Brass 2 & Teflon \\
\cline { 1 - 2 }$c m$ & $c m$ & $c m$ \\
2.5380 & 2.5412 & 2.4484 \\
2.5396 & 2.5396 & 2.4488 \\
2.5424 & 2.5374 & $\cdots$ \\
\cline { 1 - 2 } Mean: 2.5400 & 2.5394 & 2.4486 \\
\hline
\end{tabular}

and allowed to become stable. The manometers were read and the rate of flow was measured at the volumetric tank. The procedure was repeated for a number of rates until the desired range was covered.

During the testing, it became apparent that mineral deposits from the water were accumulating on the walls of both the Teflon and brass tubing. Therefore the system was periodically disassembled and the tubes were cleaned by drawing swabs of absorbent cotton through them until the deposits were removed.

\section{Experimental Results}

The results of resistance measurements are presented in figures 4 to 15 , inclusive, and summarized in tables 4, 5, and 6. All results are expressed in terms of the customary resistance coefficient $\lambda$, defined by

$$
\Delta H=\lambda \frac{x_{2}-x_{1}}{d} \frac{U^{2}}{2 g},
$$

where $\Delta H$ is the loss of head of water over the distance $x_{2}-x_{1}, d$ is the diameter of the tube, $U$ is the mean velocity over the cross section determined from volume flow, and $g$ is the acceleration of gravity. In all cases $\lambda$ is a function of the Reynolds number, $R$, expressed as $R=U d / \nu$, where $\nu$, the kinematic viscosity, is found from the temperature of the water.

The various regimes of pipe flow in the entrance length and in the fully developed regions are represented in the figures. Because it is of interest to know how the resistance coefficient in one type and section of tube compares to that in another, the $\lambda$ 's are identified by the respective sections as $\lambda_{1} \ldots \lambda_{8}$. Each of these is a mean $\lambda$ for the length between two piezometer openings with positions specified by $x_{1}$ and $x_{2}$ in table 2. For example, $\lambda_{1}$ applies to the farthest upstream length of the first brass tube between the piezometer openings at $x_{1}$ and $x_{2}$. Following this system, $\lambda_{4}$ and $\lambda_{5}$ apply to the Teflon tube.

The results of the first series of measurements are presented in figures 4 to 9 , inclusive. The curves represented by the circle symbols indicate the results of gravity flow from the constant-level tank, whereas the curves shown by the squares were obtained by using the pump to reach the higher values of Reynolds number. The measurements here were conducted under conditions where the entrance disturbances were suppressed as much as possible by the wellrounded entrance cone. The result was a consider-
TABLE 2. Location of piezometer openings

\begin{tabular}{|c|c|c|c|}
\hline Tube & Segment & ${ }^{a} x_{1}$ & ${ }^{a} x_{2}$ \\
\hline $\begin{array}{l}\text { Brass } 1 \\
\text { Do } \\
\text { Teflon } \\
\text { Do } \\
\text { Brass } 2 \\
\text { Do }\end{array}$ & $\begin{array}{l}1 \\
2 \\
4 \\
5 \\
7 \\
8\end{array}$ & $\begin{array}{r}c m \\
74.00 \\
185.71 \\
322.72 \\
434.50 \\
566.61 \\
678.33\end{array}$ & $\begin{array}{c}c m \\
185.71 \\
302.32 \\
434.50 \\
546.26 \\
678.33 \\
790.01\end{array}$ \\
\hline
\end{tabular}

a $x$ is the distance from the entrance.

able extent of laminar flow throughout most of the entrance length. The laminar, transitional, and turbulent regimes are included on each curve. In the transition region the coefficient rises with Reynolds number as more and more of the flow in the particular tube segment is in the turbulent state. A plausible concept of the transition regime is a succession of laminar and turbulent states passing down the tube. The form of the coefficient curve in the transition region will depend on the change in the relative amounts of each with Reynolds number. As seen by comparing the figures, this change tends to be more gradual and to occur at higher Reynolds numbers in the upstream segments than in the downstream segments. There is no evidence that the material of the tube had anything to do with this condition.

For the entrance region, curves have been drawn in accordance with Schiller's theory for the development of Poiseuille-type flow. ${ }^{3}$ According to this theory the mean $\lambda$ between two sections $x_{1}$ and $x_{2}$ apart, where $x_{1}$ and $x_{2}$ are measured from the beginning of the tube (the point where the boundary layer begins), is given by

$-$

$$
\lambda=\left(\xi_{2}-\xi_{1}\right) d /\left(x_{2}-x_{1}\right),
$$

where $\xi=f(2 x / R d), d$ is the diameter of the tube, and $R$ is the Reynolds number. Values of the function $f$ are given in table 3 .

\begin{tabular}{|c|c|c|c|}
\hline$\epsilon$ & $2 x / R d$ & $\epsilon$ & $2 x / R d$ \\
\hline $\begin{array}{l}0 \\
0.21 \\
.44 \\
.69 \\
.96 \\
1.25 \\
1.56\end{array}$ & $\begin{array}{l}0 \\
0.000375 \\
.0018625 \\
.00445 \\
.008325 \\
.0135 \\
.019875\end{array}$ & $\begin{array}{l}1.89 \\
2.24 \\
2.4225 \\
2.61 \\
2.8025 \\
3.00\end{array}$ & $\begin{array}{l}.02740 \\
.03625 \\
.041075 \\
.0462 \\
.051725 \\
.0575\end{array}$ \\
\hline
\end{tabular}

TABLE 3. Functions for laminar entrance length (Schiller)

Relationship (17) holds for $x \leq 0.0288 R d$. For $x \geq 0.0288 R d$ the Poiseuille regime is established, and

$$
\lambda=64 / R \text {. }
$$

Formulas (17) and (18) apply only when the flow is laminar.

${ }^{3}$ L. Schiller, Forschungsarbeiten des ver. Deutsch. Ing. No. 248, p. 21 (1922) 
Curves computed by these formulas are shown in figures 4 to 9 . In the first segment of brass tube 1 and in the last two segments of brass tube 2 the observations are in reasonably good agreement with computed values. In the remaining segments the observed points are higher than the computed curves. As far as the main objective of the experiment is concerned, this lack of agreement with theory is not of primary significance. If there is any connection with the material of the tube, the discrepancy is the greater in the Teflon. Any evidence of slip would appear in the opposite direction.

In the fully developed turbulent region, a standard of comparison is the Blasius law,

$$
\lambda=0.3164 R^{-1 / 4} \text {. }
$$

This curve is represented in figures 4 to 9 by the dashed line. The most apparent discrepancy is that appearing just after completion of transition, where the value of $\lambda$ is noticeably greater than that computed by the Blasius law. As regards a difference between $\lambda$ for Teflon and brass, none can be found. This may be seen by examining the data of table 4 .

Following the first series of measurements, a second series was run for the purpose of obtaining a larger range of Reynolds number. Here the pump was used at all times at the exit end of the system to extend the upper limit, and trip wires were placed in the entrance cone to initiate the turbulent regime at lower Reynolds numbers.

TABLE 4. Resistance coefficients from various segments (series 1)

\begin{tabular}{|c|c|c|c|c|c|c|c|}
\hline \multirow{2}{*}{$R$} & \multicolumn{2}{|c|}{ Upstream brass } & \multicolumn{2}{|c|}{ Teflon } & \multicolumn{2}{|c|}{$\begin{array}{c}\text { Downstream } \\
\text { brass }\end{array}$} & \multirow{2}{*}{$\frac{\begin{array}{c}\text { Blasius } \\
\text { law }\end{array}}{\lambda}$} \\
\hline & $\lambda_{1}$ & $\lambda_{2}$ & $\lambda_{4}$ & $\lambda_{5}$ & $\lambda_{7}$ & $\lambda_{8}$ & \\
\hline $\begin{array}{l}20,000 \\
30,000 \\
40,000 \\
50,000 \\
60,000\end{array}$ & $\begin{array}{r}0.0267 \\
.0241 \\
.0224 \\
.0212 \\
.0203\end{array}$ & $\begin{array}{r}0.0272 \\
.0279 \\
.0222 \\
.0210 \\
.0202\end{array}$ & $\begin{array}{r}0.0282 \\
.0249 \\
.0228 \\
.0214 \\
.0203\end{array}$ & $\begin{array}{r}0.0272 \\
.0241 \\
.0224 \\
.0212 \\
.0203\end{array}$ & $\begin{array}{r}0.0277 \\
.0244 \\
.0223 \\
.0210 \\
.0200\end{array}$ & $\begin{array}{r}0.0275 \\
.0244 \\
.0225 \\
.0213 \\
.0205\end{array}$ & $\begin{array}{r}0.0266 \\
.0240 \\
.0224 \\
.0212 \\
.0205\end{array}$ \\
\hline $\begin{array}{r}70,000 \\
80,000 \\
90,000 \\
100,000 \\
120,000\end{array}$ & $\begin{array}{l}.0196 \\
.0190 \\
.0185 \\
.0182 \\
.0174\end{array}$ & $\begin{array}{l}.0196 \\
.0191 \\
.0186 \\
.0181 \\
.0176\end{array}$ & $\begin{array}{l}.0195 \\
.0188 \\
.0183 \\
.0178 \\
.0171\end{array}$ & $\begin{array}{l}.0196 \\
.0191 \\
.0186 \\
.0183 \\
.0176\end{array}$ & $\begin{array}{l}.0193 \\
.0187 \\
.0182 \\
.0177 \\
.0172\end{array}$ & $\begin{array}{l}.0197 \\
.0191 \\
.0186 \\
.0182 \\
.0175\end{array}$ & $\begin{array}{l}.0195 \\
.0188 \\
.0183 \\
.0178 \\
.0170\end{array}$ \\
\hline 150,000 & .0166 & .0168 & .0163 & .0167 & .0165 & .0166 & .0161 \\
\hline
\end{tabular}

The results for the second series are shown in figures 10 to 15 , inclusive, and in tables 5 and 6 . Here again no difference is to be found between the resistance coefficients of Teflon and brass. This may be seen in table 5 by comparing values of $\lambda$, and in table 6 by comparing values of the coefficient $A$, pertaining to the formula

$$
\lambda=A R^{-1 / 4} .
$$

The closely linear character of the curves in figures 10 to 15 indicates that formula $(20)$ is a close approximation over the range of Reynolds number 4,000 to 120,000 , the latter being the upper limit of the experiment.
TABLE 5.-Resistance coefficients from various segments

\begin{tabular}{|c|c|c|c|c|c|c|}
\hline \multirow{2}{*}{$R$} & \multicolumn{2}{|c|}{ Upstream brass } & \multicolumn{2}{|c|}{ Teflon } & \multicolumn{2}{|c|}{ Downstream brass } \\
\hline & $\lambda_{1}$ & $\lambda_{2}$ & $\lambda_{4}$ & $\lambda_{5}$ & $\lambda_{7}$ & $\lambda_{8}$ \\
\hline $\begin{array}{r}4,000 \\
6,000 \\
8,000 \\
10,000 \\
20,000\end{array}$ & $\begin{array}{r}0.0406 \\
.0365 \\
.0338 \\
.0319 \\
.0267\end{array}$ & $\begin{array}{l}0.0420 \\
.0374 \\
.0345 \\
.0322 \\
.0272\end{array}$ & $\begin{array}{r}0.0403 \\
.0369 \\
.0345 \\
.0327 \\
.0275\end{array}$ & $\begin{array}{r}0.0412 \\
.0369 \\
.0341 \\
.0321 \\
.0268\end{array}$ & $\begin{array}{r}0.0421 \\
.0373 \\
.0344 \\
.0323 \\
.0268\end{array}$ & $\begin{array}{r}0.0414 \\
.0373 \\
.0347 \\
.0326 \\
.0268\end{array}$ \\
\hline $\begin{array}{l}30,000 \\
40,000 \\
50,000 \\
60,000 \\
70,000\end{array}$ & $\begin{array}{l}.0241 \\
.0225 \\
.0212 \\
.0204 \\
.0197\end{array}$ & $\begin{array}{l}.0246 \\
.0228 \\
.0216 \\
.0206 \\
.0198\end{array}$ & $\begin{array}{l}.0246 \\
.0228 \\
.0216 \\
.0206 \\
.0199\end{array}$ & $\begin{array}{l}.0240 \\
.0225 \\
.0213 \\
.0204 \\
.0198\end{array}$ & $\begin{array}{l}.0241 \\
.0224 \\
.0212 \\
.0203 \\
.0196\end{array}$ & $\begin{array}{l}.0242 \\
.0225 \\
.0214 \\
.0205 \\
.0197\end{array}$ \\
\hline $\begin{array}{r}80,000 \\
90,000 \\
100,000 \\
120,000\end{array}$ & $\begin{array}{l}.0192 \\
.0186 \\
.0182 \\
.0176\end{array}$ & $\begin{array}{l}.0192 \\
.0186 \\
.0182 \\
.0175\end{array}$ & $\begin{array}{l}.0192 \\
.0187 \\
.0183 \\
.0175\end{array}$ & $\begin{array}{l}.0192 \\
.0187 \\
.0183 \\
.0177\end{array}$ & $\begin{array}{l}.0189 \\
.0184 \\
.0180 \\
.0173\end{array}$ & $\begin{array}{l}.0191 \\
.0186 \\
.0182 \\
.0174\end{array}$ \\
\hline
\end{tabular}
(series 2)

\begin{tabular}{|c|c|c|c|c|c|c|}
\hline$R$ & $\lambda_{1} R^{1 / 4}$ & $\lambda_{2} R^{1 / 4}$ & $\lambda_{4} R^{1 / 4}$ & $\lambda_{5} R^{1 / 4}$ & $\lambda_{7} R^{1 / 4}$ & $\lambda_{8} R^{1 / 4}$ \\
\hline $\begin{array}{r}4,000 \\
6,000 \\
8,000 \\
10,000 \\
20,000\end{array}$ & $\begin{array}{r}0.3229 \\
.3212 \\
.3196 \\
.3190 \\
.3174\end{array}$ & $\begin{array}{r}0.3333 \\
.3292 \\
.3263 \\
.3220 \\
.3234\end{array}$ & $\begin{array}{r}0.3198 \\
.3248 \\
.3263 \\
.3270 \\
.3269\end{array}$ & $\begin{array}{r}0.3269 \\
.3248 \\
.3225 \\
.3210 \\
.3186\end{array}$ & $\begin{array}{r}0.3341 \\
.3283 \\
.3253 \\
.3230 \\
.3186\end{array}$ & $\begin{array}{r}0.3285 \\
.3283 \\
.3282 \\
.3260 \\
.3186\end{array}$ \\
\hline $\begin{array}{l}30,000 \\
40,000 \\
50,000 \\
60,000 \\
70,000\end{array}$ & $\begin{array}{r}.3171 \\
.3182 \\
.3170 \\
.3192 \\
.3204\end{array}$ & $\begin{array}{l}.3237 \\
.3224 \\
.3229 \\
.3223 \\
.3220\end{array}$ & $\begin{array}{l}.3237 \\
.3224 \\
.3229 \\
.3223 \\
.3236\end{array}$ & $\begin{array}{l}.3158 \\
.3182 \\
.3185 \\
.3192 \\
.3220\end{array}$ & $\begin{array}{l}.3171 \\
.3167 \\
.3170 \\
.3177 \\
.3188\end{array}$ & $\begin{array}{l}.3184 \\
.3182 \\
.3200 \\
.3208 \\
.3204\end{array}$ \\
\hline $\begin{array}{r}80,000 \\
90,000 \\
100,000 \\
120,000\end{array}$ & $\begin{array}{l}.3228 \\
.3221 \\
.3236 \\
.3275\end{array}$ & $\begin{array}{l}.3228 \\
.3221 \\
.3236 \\
.3257\end{array}$ & $\begin{array}{l}.3228 \\
.3238 \\
.3254 \\
.3257\end{array}$ & $\begin{array}{l}.3228 \\
.3238 \\
.3254 \\
.3294\end{array}$ & $\begin{array}{l}.3178 \\
.3187 \\
.3200 \\
.3219\end{array}$ & $\begin{array}{l}.3212 \\
.3221 \\
.3236 \\
.3238\end{array}$ \\
\hline Mean_- & 0. 3206 & 0.3244 & 0.3241 & 0.3221 & 0.3211 & 0.3227 \\
\hline
\end{tabular}

TABle 6. Values of $A$ for $\lambda=A R^{-1 / 4}$

With regard to the question of the effect of the material of the tube, the mean values of $A$ in this range are $A$ (brass) $=0.3222$ and $A$ (Teflon) $=0.3230$. Obviously no effect of slip is discernible.

\section{Discussion of Results}

The discrepancies between theory and experiment found in the entrance length and the small deviations from the Blasius law show the importance of a direct comparison between Teflon and a wetting material in reaching a valid decision concerning the presence or absence of a slip effect. This is particularly true where the objective is to detect even small effects if they should exist.

As previously noted, there were no differences beyond the experimental scatter between the behavior of Teflon and brass in the fully developed turbulent regions. In the entrance length, different segments of tubing showed varying amounts of disagreement with theory. Perhaps the disagreement is slightly more for the Teflon than for the brass. If the difference had been in such a direction as to suggest a lower value of $\lambda$ for Teflon than for brass, there may have been a hint of a slip effect in the laminar regime. However, the difference suggests a higher value of $\lambda$, in direct opposition to a slip effect. 
The mean values of the coefficient $A$ in formula (20) for Teflon and brass differ by only 0.25 percent, with that for Teflon being the higher. Because the separate mean values in table 6 differ by more than this, no significance can be attached to the slightly higher values of $A$ for Teflon. The mean of all values of $A$ in table 6 is 0.3225 . This is about 2 percent higher than the generally accepted value of 0.3164 . Differences of this order are to be expected in experiments of this type.

The larger discrepancies occurring in the laminar regime and in the turbulent regime just after the completion of transition, while not significant in the main objective, are nevertheless of interest. If a transition region consists of a succession of laminar and turbulent states following one another in time, there would be no reason to suppose that the turbulent coefficient would be abnormally high at the Reynolds number where all laminar states had just disappeared. It is believed therefore that this effect is probably associated with the high value of $\lambda$ in the laminar regime, and that this in turn is the result of some entrance condition. Perhaps there was some swirl remaining in the flow from the bend $8 \mathrm{ft}$ upstream from the entrance cone. Unfortunately no velocity surveys were made to determine the actual condition of the entering flow.

The absence of a measurable slip effect implies that the characteristic length $l$ is zero for Teflon as it is for a wetted material. This evidently means that adhesion, even though weak compared to the cohesion of water, amounts to a contact so complete as to preclude relative movement. Apparently the nature of the contact is such that water can be pulled free by a normal force, but its grip cannot be broken by a tangential force applied by viscous shear. It does not necessarily follow that this would be true for all flow conditions and all hydrophobic materials or surface conditions.

The author acknowledges the assistance given and contributions made during this investigation by G. B. Schubauer and G. H. Keulegan. He is particularly grateful for their suggestions regarding the form and content of this report.

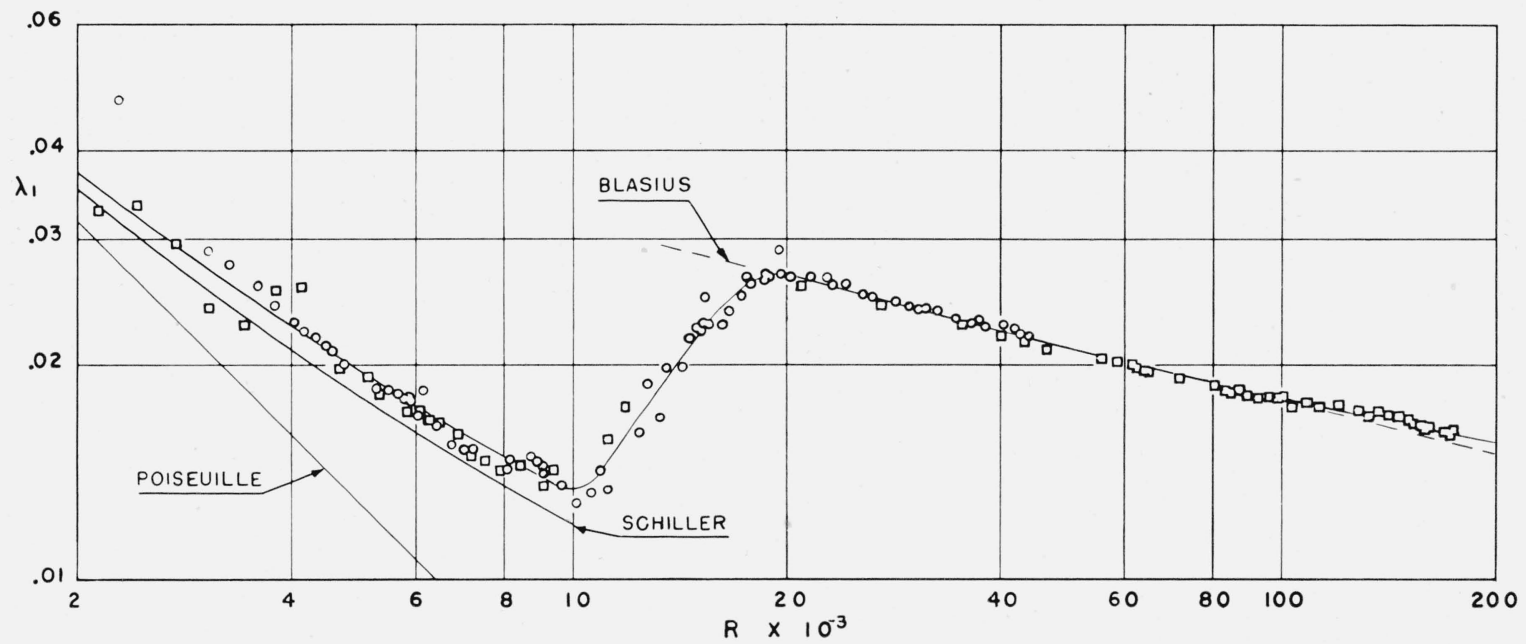

Figure 4. Coefficient of resistance, segment 1 , brass tube 1 .

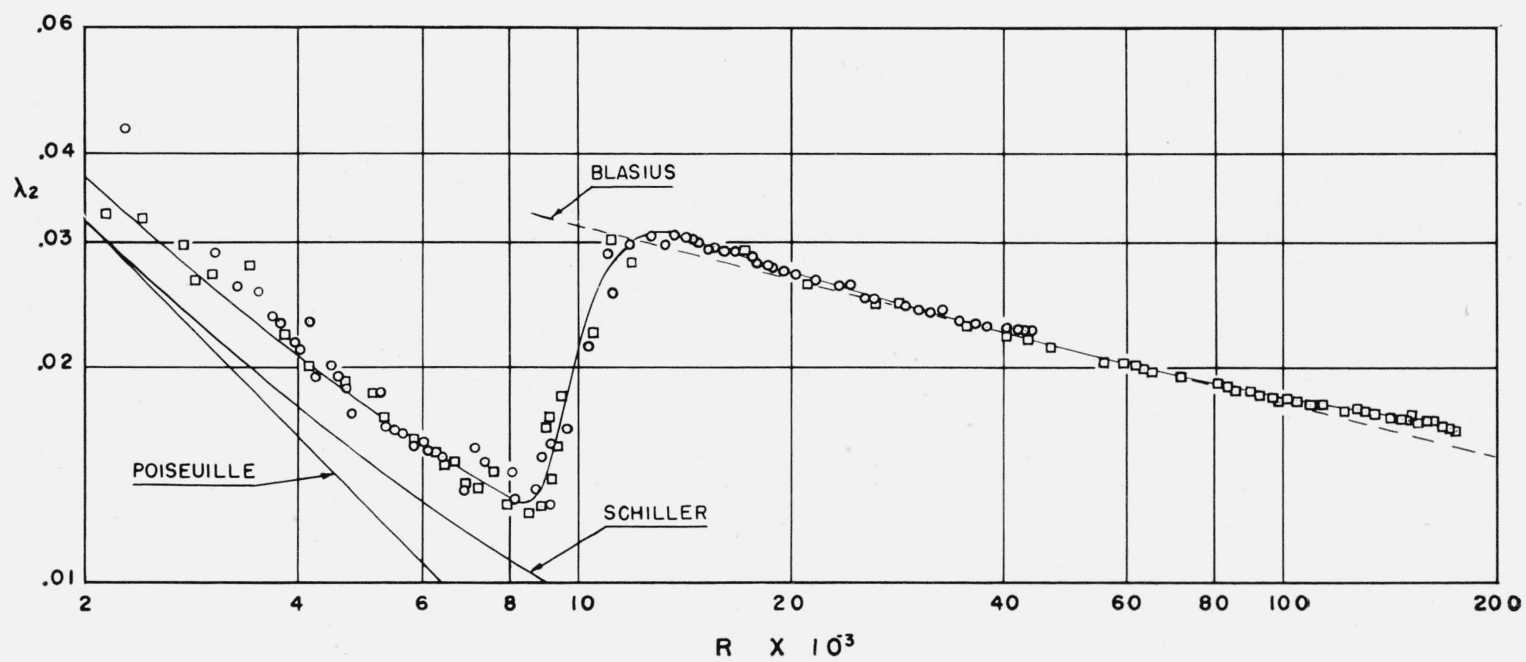

Figure 5. Coefficient of resistance, segment 2, brass tube 1 . 


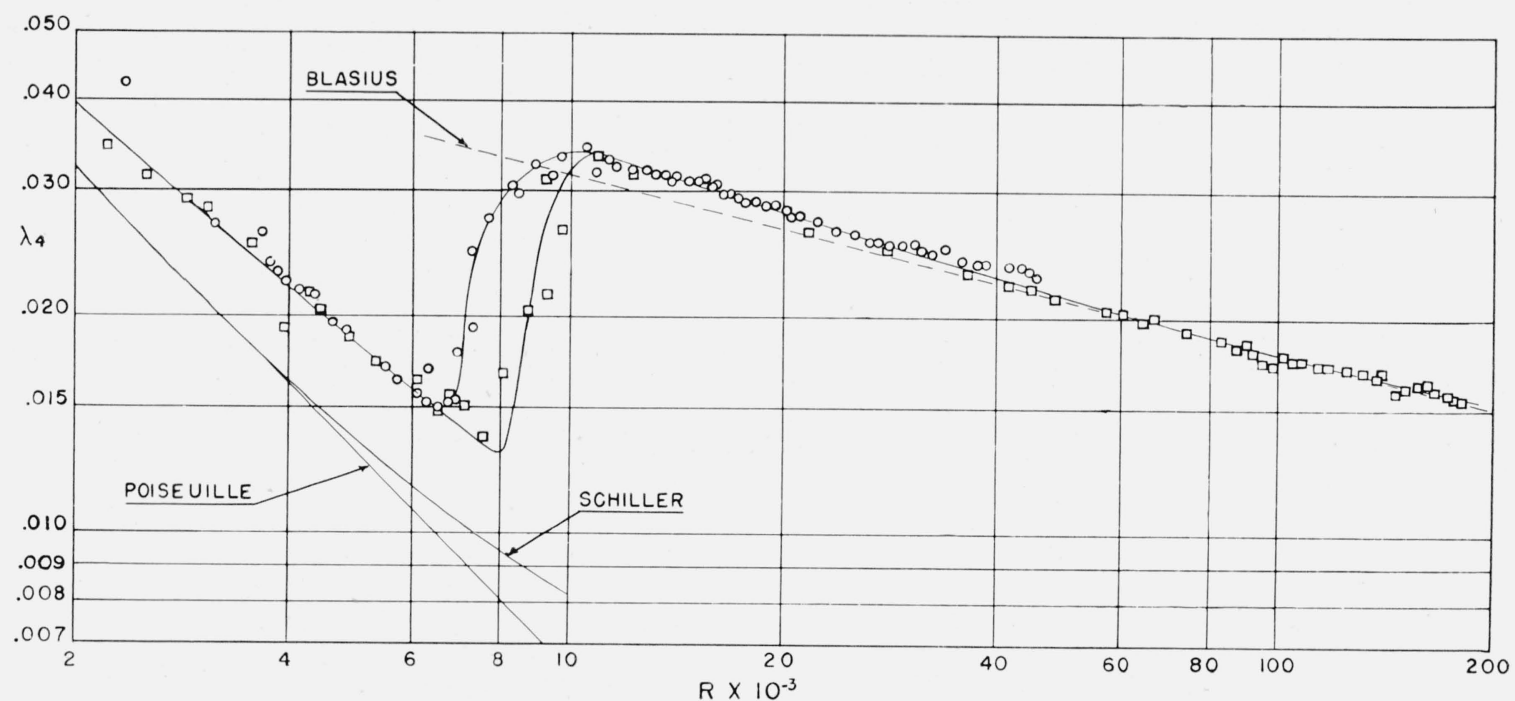

Figure 6. Coefficient of resistance, segment 4, Teflon tube.

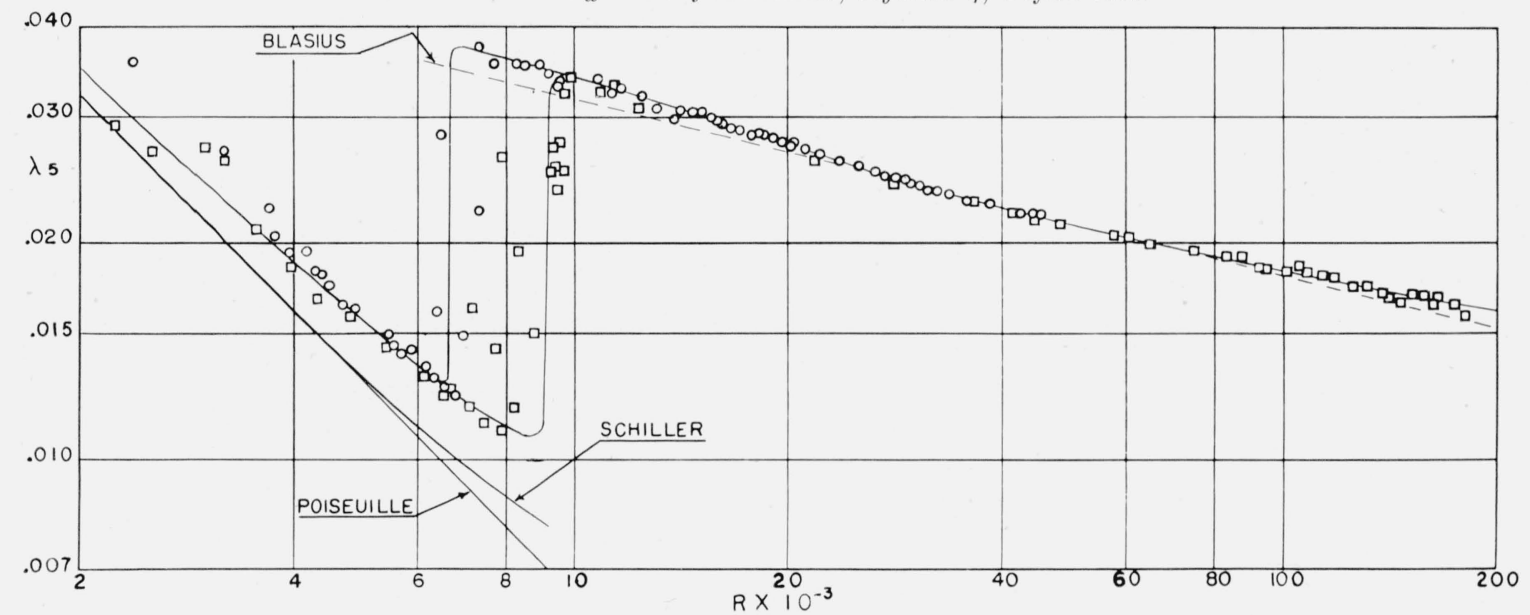

Figure 7. Ccefficient of resistance, segment 5, Teflon tube.

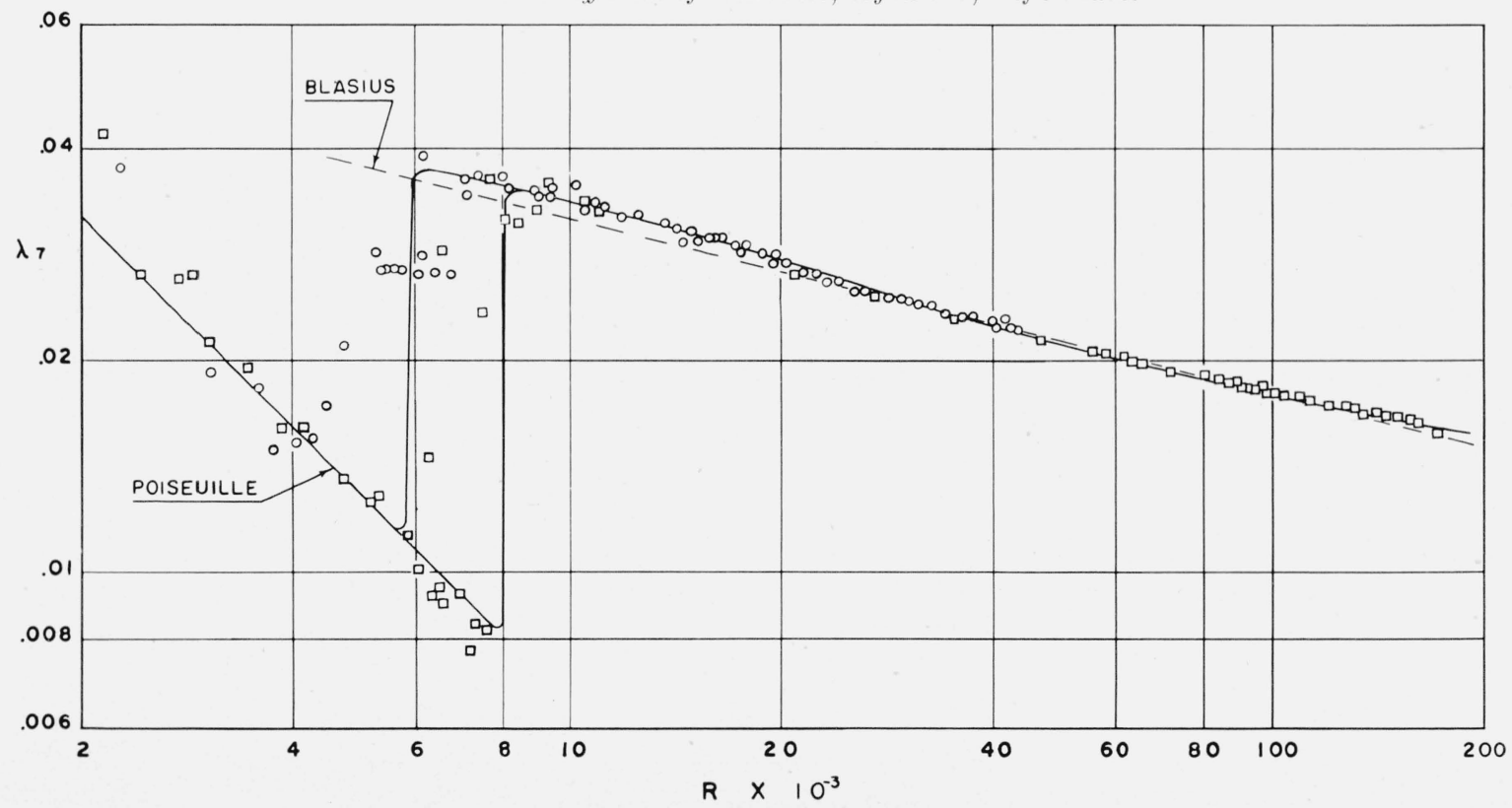

Figure 8. Coefficient of resistance, segment 7 , brass tube 2. 


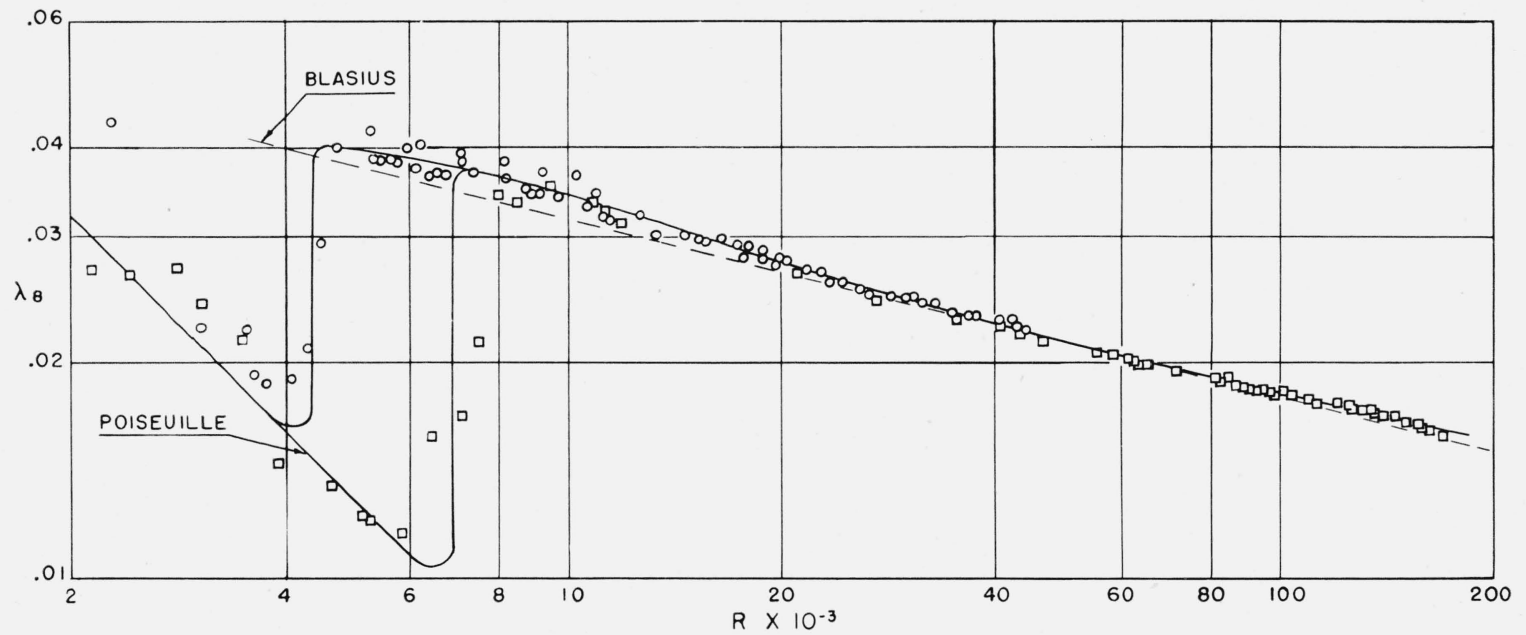

Figure 9. Coefficient of resistance, segment 8, brass tube 2.

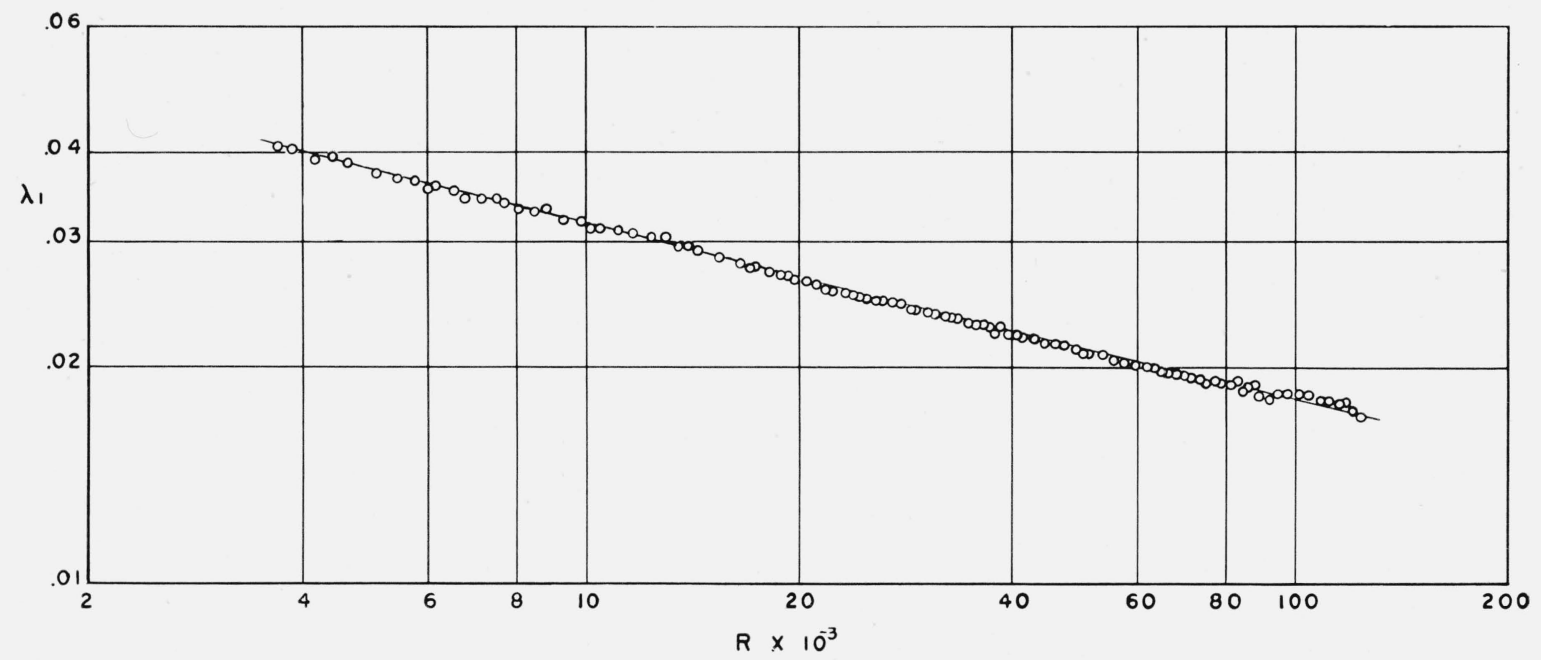

Figure 10. Coefficient of resistance, segment 1, brass tube 1.

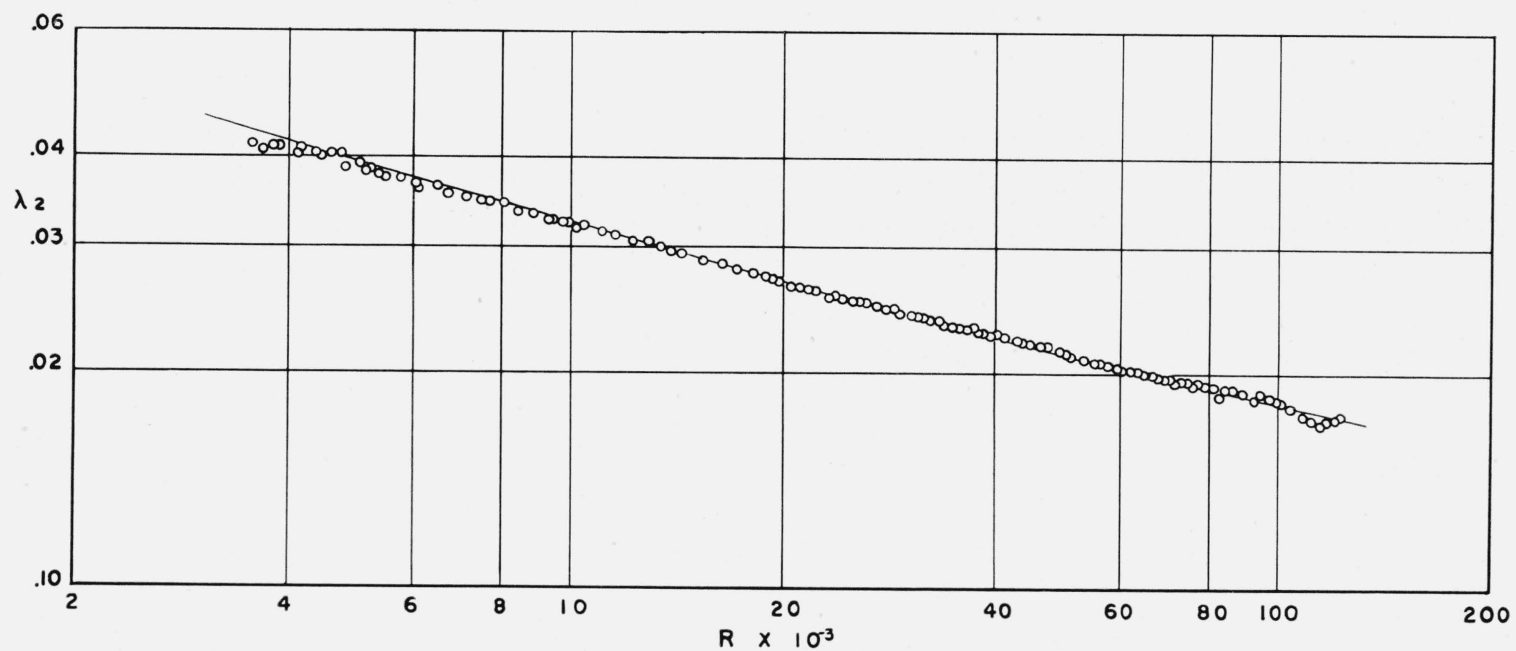

FiguRE 11. Coefficient of resistance, segment 2, brass tube 1. 


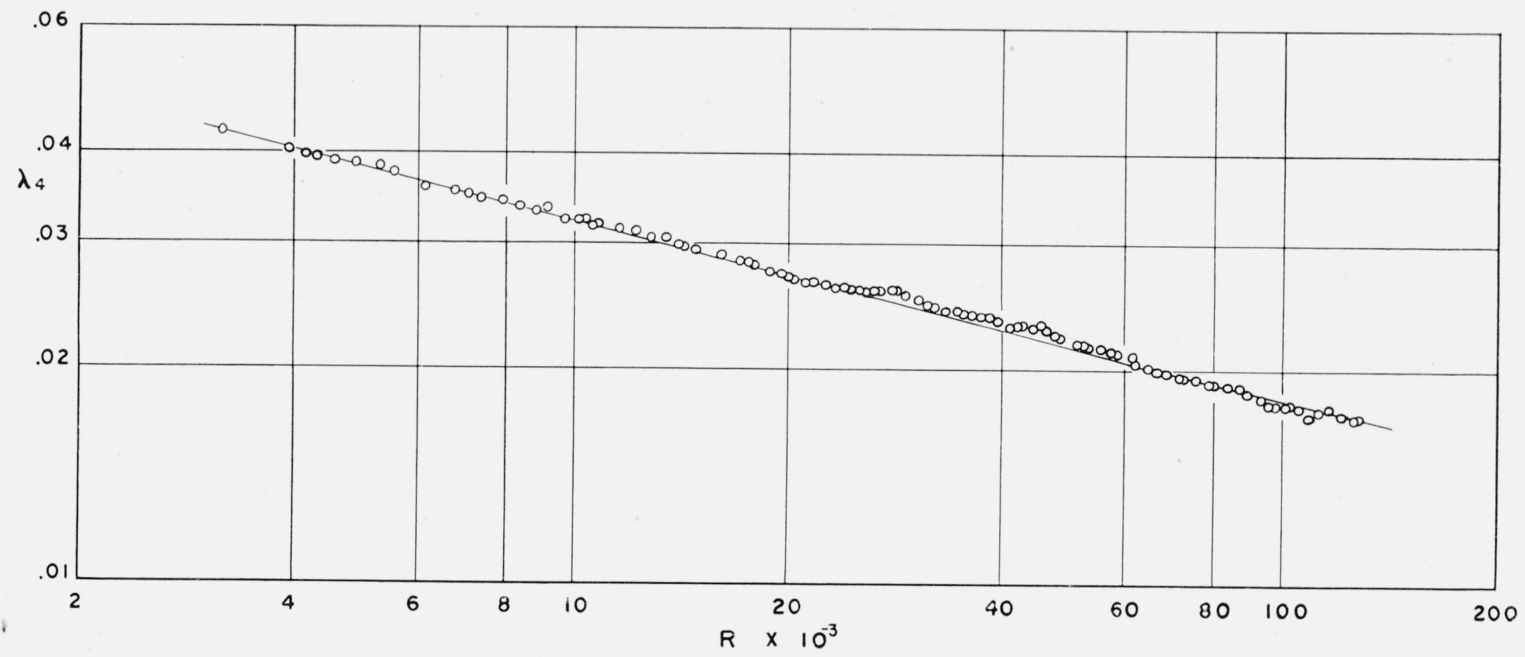

Figure 12. Coefficient of resistance, segment 4, Teflon tube.

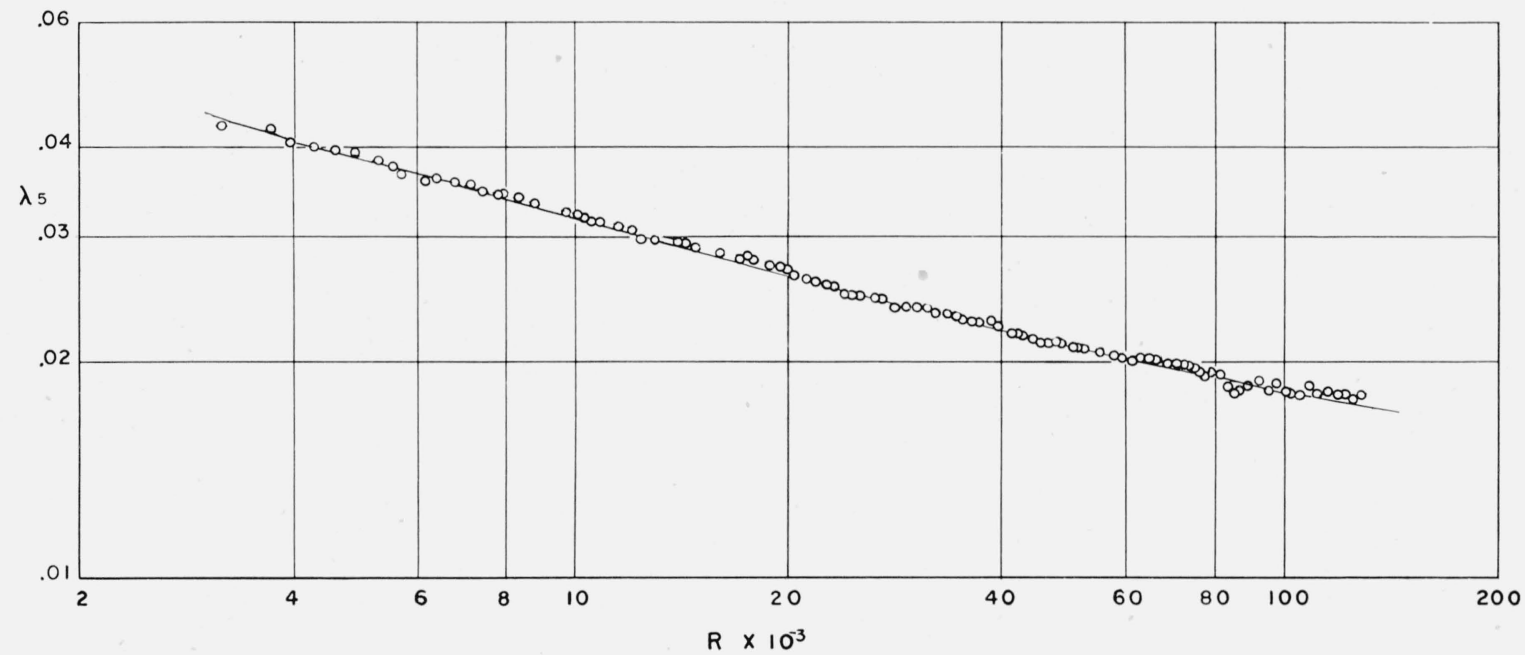

Figure 13. Coefficient of resistance, segment 5, Teflon tube.

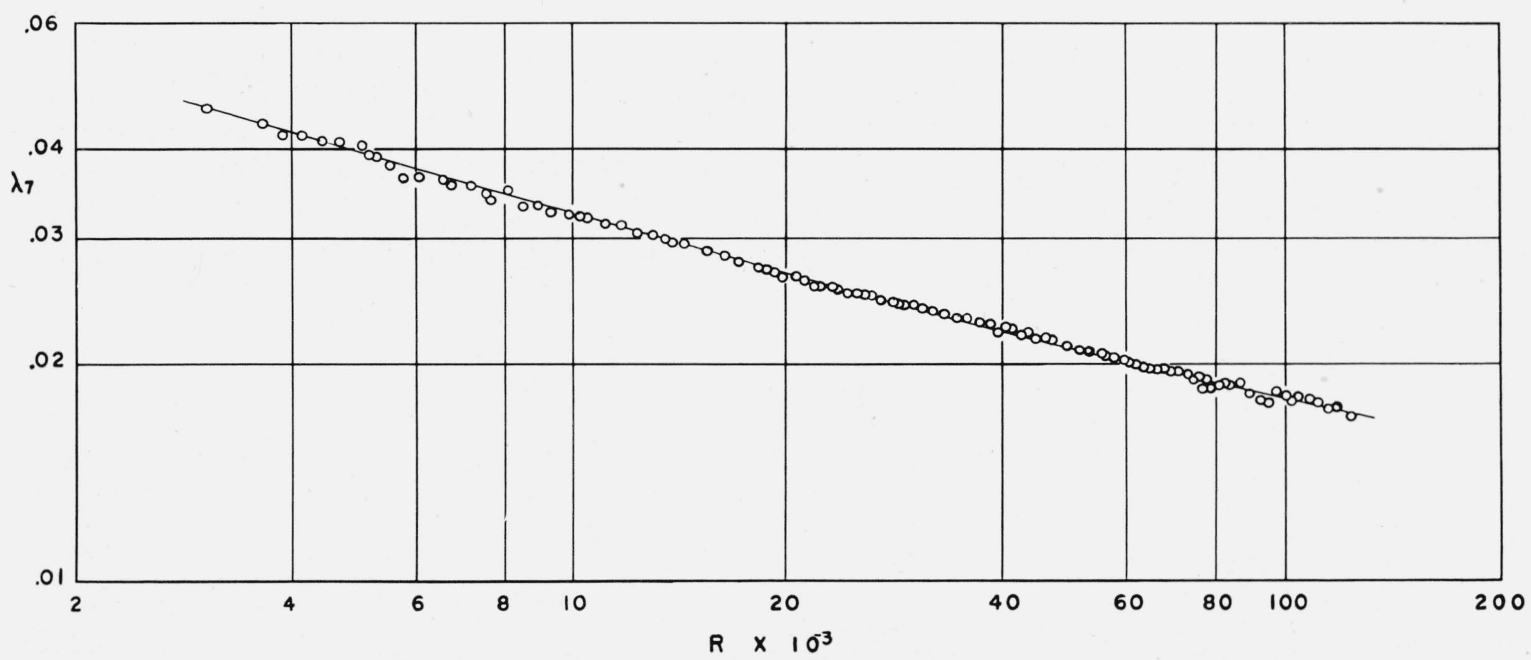

FiguRE 14. Coefficient of resistance, segment 7 , brass tube 2. 


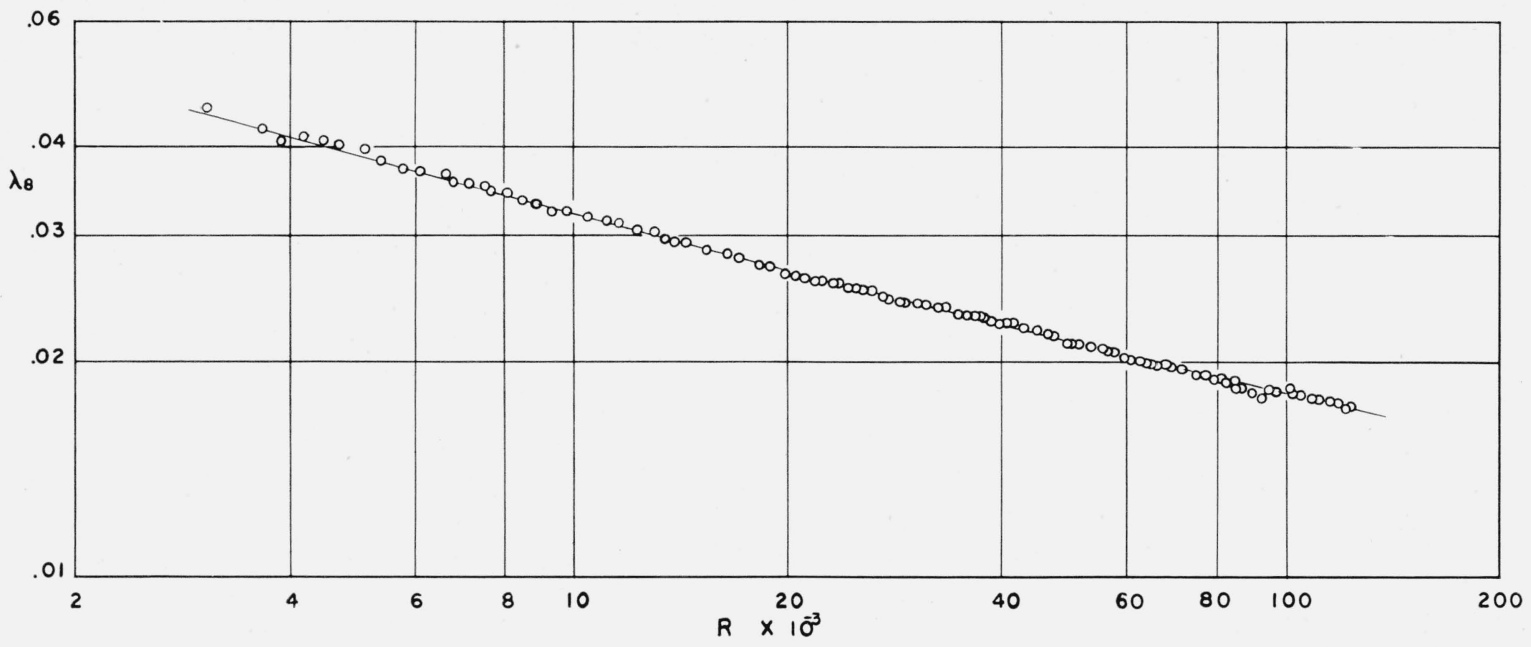

Figure 15. Coefficient of resistance, segment 8, brass tube 2.

Washington, August 3, 1956. 